\title{
ANTI-OESTROGENIC AND ANTIFERTILITY PROPERTIES OF SOME 4,4'-DIHYDROXYBIBENZYLS
}

\author{
C. W. EMmens, D. J. COLlins, J. J. HOBBS, B. G. MilleR \\ AND W. H. OWEN
}

Department of Veterinary Physiology, University of Sydney, Sydney, N.S.W., Australia

(Received 8th October 1966, publication delayed at Authors' request)

\begin{abstract}
Summary. A number of 4,4'-dihydroxybibenzyls has been prepared, with resolution of some isomers. Most are pro-oestrogens and all are anti-oestrogens of varying potency. Dextro- and laevo- $\alpha, \alpha^{\prime}$-dimethyl-4,4'dihydroxybibenzyl (D- and L-DMA) have the same anti-oestrogenic and antifertility potencies in mice, but threo- and erythro- $\alpha$-ethyl- $\alpha^{\prime}$-methyl4,4'-dihydroxybibenzyl (threo- and erythro-MEA) differ markedly in all properties examined. Erythro-MEA, although a fairly potent pro-oestrogen, is highly anti-oestrogenic intravaginally and a potent antifertility agent with an MED of less than $1 \mu \mathrm{g} /$ day. DL-Hexoestrol (DL-DEA) is also a potent anti-oestrogen and fairly potent antifertility agent, with an MED about $10 \mu \mathrm{g} /$ day.

This series of compounds contrasts with the stilbene-4,4'-diols in possessing members with exceptional antifertility potency, not readily explained by their oestrogenic activities.
\end{abstract}

\section{INTRODUCTION}

In various recent publications from this Department, the anti-oestrogenic and antifertility effects of various compounds related to diethylstilboestrol and hexoestrol have been described, primarily in the albino mouse. In some, the effects of isomerism on potency have been investigated, but no thorough investigation was possible without more chemical work. Thus, cis- and transdimethylstilboestrol diacetate (DMS diacetate) have approximately the same potency as antifertility compounds (Martin, Cox \& Emmens, 1963), although they differ 10-fold in anti-oestrogenic potency (Emmens, Cox \& Martin, 1959).

The general question of correlation between oestrogenic, anti-oestrogenic and antifertility potency has not so far been much illuminated by such comparative studies in non-steroidal compounds, although in steroids the position is clearer. However, it was shown by Emmens (1965b) that changes in the relative oestrogenic activities of diethylstilboestrol (DES) and DMS by different routes of administration in different species were accompanied by closely correlated changes in antifertility activity. This, and studies by Stone \& Emmens (1964a, b) make it seem very likely that DMS, at least, owes its antifertility activity to oestrogenicity, not to its anti-oestrogenic properties.

The series of 4,4'-dihydroxybibenzyls (compounds related to hexoestrol), 
obtained by saturation of the olefinic bond of the corresponding stilbene derivatives, exist either as

(i) a single pair of optical isomers (DL),

(ii) a meso form and a De pair, or

(iii) as erythro and threo isomers (each DL pairs), depending on whether they are derived from

(a) $\alpha$-monosubstituted stilbenes (e.g. $\alpha$-methylstilbene-4,4'-diol, MHs),

(b) symmetrically $\alpha, \alpha^{\prime}$-disubstituted stilbenes (e.g. $\alpha, \alpha^{\prime}$-dimethylstilbene-4,4'diol, DMs), or

(c) stilbenes bearing different $\alpha$ - and $\alpha^{\prime}$-substituents (e.g. $\alpha$-ethyl- $\alpha^{\prime}$-methylstilbene-4,4'-diol, MEs).

Some of the compounds in this series have been tested previously, and maximum anti-oestrogenic potency was shown by meso-butoestrol (meso-DMA). The less active DL-DMA has now been resolved into its $D$ and $L$ forms to test for stereospecificity in its anti-oestrogenic activity. Pure erythro- and threo- $\alpha$-ethyl$\alpha^{\prime}$-methyl-4,4'-dihydroxybibenzyl (MEA) have now been prepared, although neither of these has yet been resolved into its $\mathrm{D}$ and $\mathrm{L}$ forms. The preparation and testing of these compounds are reported below.

\section{MATERIALS AND METHODS}

Randomly bred mice of the QS (Quackenbush) strain were used in all tests. Vaginal smear tests were as described by Emmens (1957) and scored according to whether 0,1 or 2 positive smears were recorded in a total of two smears per animal in groups of ten animals. Tests of anti-oestrogenic activity were all against oestradiol. Tests of antifertility activity were also conducted with ten mice per group, as described by Martin et al. (1963). In each case the results of injection on Days 1 to 3 and 4 to 6 after mating are considered together to give a mean daily dose. Any differences between doses needed in the two periods are small, but in favour of a somewhat greater effectiveness in the later period. Solutions were prepared immediately before use from crystalline solids or oils, or from ethanolic stock solutions. All preparations were made in the Department.

Statistical treatment of results has been omitted in this paper because precise estimates of relative potency or of MEDs and their limits of error are not needed when the important contrasts involve one or more orders of magnitude. Each compound has been examined in sufficient detail to ensure that comparison with the others is meaningful, several groups of animals having been placed in each test, which was often replicated on other occasions.

Following earlier papers, the analogues of hexoestrol are denoted by threeletter groups ending in $\mathrm{A}$, with $\mathrm{H}=$ hydrogen, $\mathrm{M}=$ methyl, $\mathrm{E}=$ ethyl, $\mathrm{DM}=$ dimethyl, etc. Thus, DMA $=\alpha, \alpha^{\prime}$-dimethyl-4,4'-dihydroxybibenzyl. The corresponding analogues of stilboestrol are denoted by three-letter groups ending in $\mathrm{s}$.

PREPARATION OF COMPOUNDS

In the first instance (Emmens, Cox \& Martin, 1960), meso- and DL-DMA were prepared by hydrogenation of trans-DMs-diacetate in glacial acetic acid using 
platinum oxide catalyst. This hydrogenation was non-stereospecific, giving a mixture of the corresponding meso- and DL-bibenzyl diacetates which were separated by repeated fractional crystallization, then hydrolysed to the mesoand DL-4,4'-dihydroxybibenzyls.

Subsequently (Emmens, Cox \& Martin, 1964), the isomeric diacetates from the hydrogenation mixture were separated by chromatography on silica gel. Hydrolysis gave the meso- and DL-4,4'-dihydroxybibenzyls which were individually rechromatographed on silica gel, then recrystallized several times.

The above procedures are unsatisfactory for two main reasons (i) the hydrogenation is non-stereospecific, probably due to cis-trans equilibration of the stilbene diacetate under the hydrogenation conditions, necessitating tedious separation procedures; (ii) the highly active platinum oxide catalyst has probably caused some degree of reduction of the benzene rings, producing impurities which cannot readily be removed.

In fact, thin layer chromatography of the samples of meso- and DL-DMA used in previous biological assays (Emmens et al., 1964) has now shown that although neither was contaminated with detectable amounts of its diastereoisomer, each contained appreciable quantities of two highly polar impurities. Preparative thin layer chromatography of the meso-preparation enabled isolation of the two impurities, and one of these was found to have appreciable oestrogenic activity (Martin, L., personal communication). Insufficient of the DL-isomer (preparation G304C, Emmens et al., 1964) was left to carry out a similar experiment, but we believe that at least one of the impurities in this sample was probably also oestrogenic-hence the lower anti-oestrogenic activity of this preparation.

To eliminate this difficulty, the following more efficient procedure was used to prepare pure samples of the various 4,4'-dihydroxybibenzyl derivatives, whose physiological activities are reported herein.

Dimethyl ethers of both cis- and trans- stilbene-4,4'-diols are more stable than the corresponding diacetates and would be expected to maintain their stereochemical integrity during hydrogenation. Thus, stereospecific hydrogenation of cis-4,4'-dimethoxystilbenes (Ia) to meso- (or erythro) 4,4'-dimethoxybibenzyls (III), and of trans-4,4'-dimethoxystilbenes (Ib) to DL- (or threo) 4,4'-dimethoxybibenzyl derivatives (IIb), was carried out in glacial acetic acid using palladium-charcoal catalyst. By use of the latter partial benzene ring reduction was avoided.

Gas-liquid chromatography (g.l.c.) using an F \& M model 810 gas chromatograph (fitted with dual flame ionization detectors) showed that in each case the total hydrogenation product was at least $98 \%$ pure. The solid hydrogenation products were further purified by several crystallizations (usually two or three from ethanol or methanol) until none of the isomer could be detected by g.l.c.

Moreover, since the dimethyl ethers (Ia) and (Ib) are precursors in the usual synthesis of $\alpha, \alpha^{\prime}$-disubstituted stilbene-4,4'-diols such as DMS, two synthetic steps, namely, demethylation of $(I)$ and acetylation of the resulting stilbene-4,4'diols can be eliminated. This results in a considerable increase in the overall yield, and a reduction of the time involved.

Demethylation of (IIa) and (IIb) to (IIIa) and (IIIb) respectively, can be carried out cleanly without isomerization by refluxing the pure dimethyl ethers 
with a mixture of glacial acetic acid and $45 \% \mathrm{w} / \mathrm{v}$ hydrobromic acid. The resulting phenols (IIIa) and (IIIb) were recrystallized until thin layer chromatography showed only one spot.

The resolution of DL-DMA into the pure laevo-isomer $\left(\alpha_{D}-103^{\circ}\right.$, dioxan $)$ and partly resolved dextro-isomer $\left(\alpha_{\mathrm{D}}+66^{\circ}\right.$, dioxan) was achieved via the bis- $(\alpha-$ bromocamphor- $\pi$-sulphonate) according to the method of Wessely \& Welleba (1941), and Wessely, Bauer, Chwala, Plaichinger \& Schonbeck (1948). (Experimental details will be published elsewhere.)

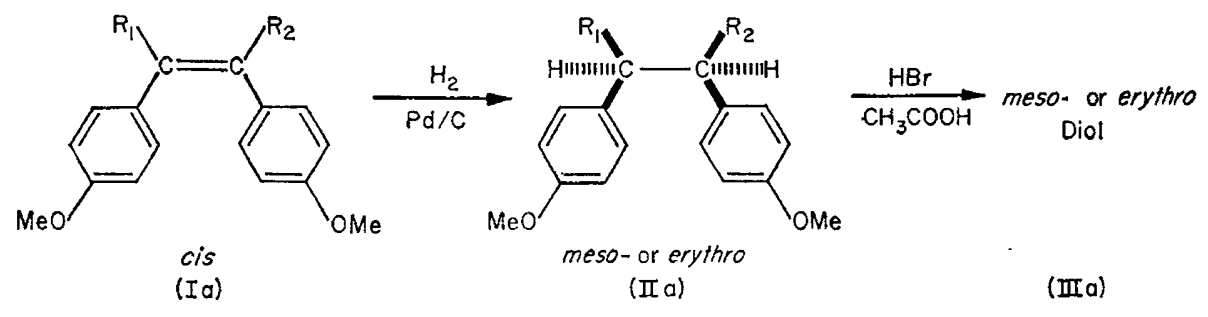

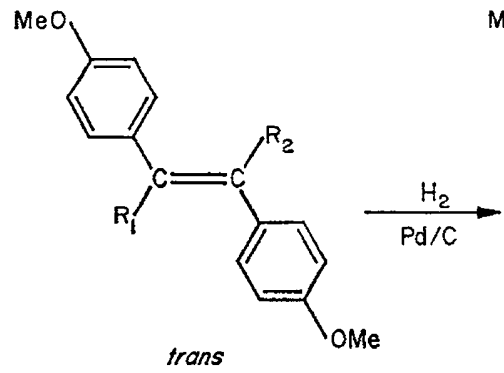

(Ib)

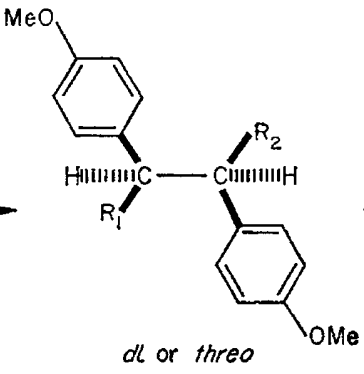

(IIb)

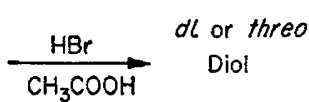

RESULTS

Of the compounds in Table 1, only мна was active subcutaneously as an antioestrogen, the MED for inhibition of $0.06 \mu \mathrm{g}$ of oestradiol-3:17 $\beta$ was $500 \mu \mathrm{g}$. The table, therefore, lists only antagonism to quantities ranging from 0.002 to 0.005 $\mu \mathrm{g}$ of oestradiol in intravaginal tests. All compounds tested in this series (except for trans-DES, quoted at the base of the table with a small group of stilbene derivatives for comparison) are pro-oestrogens, therefore their intravaginal MEDs have not always been ascertained, as it would sometimes take too much of a compound in short supply for little gain in information.

As already remarked, some dihydroxybibenzyls tend to exhibit greater antifertility potency than their oestrogenic activity would lead one to expect (Emmens et al., 1964; Emmens, 1965a). This is confirmed in Table 1, where erythro-MEA, outstandingly, has a much greater antifertility potency than its oestrogenic activity explains. Compared with trans-DMs, a member of a series in which antifertility activity appears to parallel oestrogenicity, it has some 4-fold oestrogenic activity, but more than 50 -fold antifertility activity.

Demonstration of the presence of impurities in earlier preparations of some of these compounds (see above) explains discrepancies between present findings and results previously reported (Emmens, 1965a). Thus, the specimen then 
available of DL-DMA was reported as inactive in all tests, whereas a new preparation of higher purity is now found to be weakly active in some. The compounds, meso-DMA and erythro-MEA, now fully purified perhaps for the first time, show less oestrogenic activity than earlier reported, but the discrepancy is only serious with erythro-MEA at $15 \mu \mathrm{g}$ (previously $1 \mu \mathrm{g}$ ), and anti-oestrogenic activity at 0.4 $\mu \mathrm{g}$ intravaginally (previously thought inactive, since it was not tested at this dose level because of its supposed oestrogenic potency).

\section{TABLE 1}

OESTROGENIC, ANTI-OESTROGENIC AND ANTIFERTILITY AGTIVITIES OF VARIOUS $4,4^{\prime}$,-DIHYDROXYBIBENZYLS

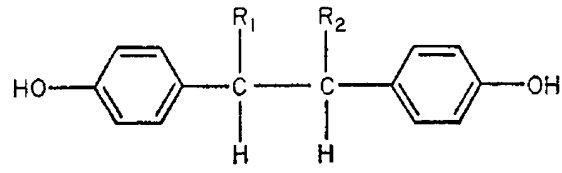

\begin{tabular}{|c|c|c|c|c|c|c|}
\hline \multirow[b]{2}{*}{$\begin{array}{l}\text { Reference } \\
\text { code }\end{array}$} & \multirow{2}{*}{\multicolumn{2}{|c|}{$\begin{array}{l}\text { Substances } \\
R_{1} \quad R_{2}\end{array}$}} & \multicolumn{4}{|c|}{ Approximate MEDs $(\mu \mathrm{g})$} \\
\hline & & & $\begin{array}{l}O_{e} \\
\text { subcut. }\end{array}$ & $\begin{array}{l}\text { enic } \\
\text { intravag. }\end{array}$ & $\begin{array}{c}\text { Anti-oestrogenic } \\
\text { intravag. }\end{array}$ & $\begin{array}{c}\text { Antifertility } \\
\text { subcut. (per day) }\end{array}$ \\
\hline $\begin{array}{l}\text { MHA } \\
\text { meso-DMA } \\
\text { DL-DMA } \\
\text { L-DMA } \\
\text { D-DMA* } \\
\text { threo-MEA } \\
\text { erythro-MEA } \\
\text { DL-DEA } \\
\text { trans-DMS } \dagger \\
\text { trans-MEs } \dagger \\
\text { trans-DEs } \dagger\end{array}$ & $\begin{array}{c}\mathrm{H} \\
\mathrm{CH}_{3} \\
\mathrm{CH}_{3} \\
\mathrm{CH}_{3} \\
\mathrm{CH}_{3} \\
\mathrm{CH}_{3} \\
\mathrm{CH}_{3} \\
\mathrm{C}_{2} \mathrm{H}_{5} \\
= \\
=\end{array}$ & $\begin{array}{l}\mathrm{CH}_{3} \\
\mathrm{CH}_{3} \\
\mathrm{CH}_{3} \\
\mathrm{CH}_{3} \\
\mathrm{CH}_{3} \\
\mathrm{C}_{2} \mathrm{H}_{5} \\
\mathrm{C}_{2} \mathrm{H}_{5} \\
\mathrm{C}_{2} \mathrm{H}_{5} \\
- \\
- \\
-\end{array}$ & $\begin{array}{r}>2000 \\
60 \\
600 \\
>1000 \\
1000 \\
1000 \\
15 \\
80 \\
60 \\
1.2 \\
0.2\end{array}$ & $\begin{array}{c}>1000 \\
>80 \\
>100 \\
>200 \\
200 \\
700 \\
25 \\
>400 \\
50 \\
3 \\
0.0004\end{array}$ & $\begin{array}{l}8 \\
0.3 \\
3 \\
3 \\
3 \\
1 \cdot 5 \\
0 \cdot 4 \\
0 \cdot 1 \\
0.2 \\
\text { inactive } \\
\text { inactive }\end{array}$ & $\begin{array}{r}>2000 \\
5 \\
100 \\
500 \\
500 \\
150 \\
<1 \\
10 \\
50 \\
1 \\
0.3\end{array}$ \\
\hline
\end{tabular}

* Not obtained optically pure.

† Included for comparison, data from previous papers, summarized in Emmens, Cox \& Martin (1962) and Emmens (1965a).

Dextro- and laevo-DMA, obtained by resolution of DL-DMA, showed approximately equal activities, which, puzzlingly, are somewhat lower than those of the original racemic mixture. However, as indicated earlier, the dextro-isomer was not obtained optically pure, and this must be taken into account.

\section{DISCUSSION}

The higher potency of meso-DMA compared with DL-DMA is parallelled by the finding that erythro-MEA is more potent in all tests than threo-MEA.

Resolution of DL-DMA has shown no significant differences in potency between its optical isomers. This is not conclusive evidence against optical stereospecificity in the anti-oestrogenic and/or antifertility activity in the $\alpha, \alpha^{\prime}$-dialkyl4,4'-dihydroxybibenzyl series because DL-DMA has such a low activity. Resolution of the more potent erythro- and threo-MEA, particularly of the former, should provide a more definitive answer to the question of optical stereospecificity. In this respect it is interesting that Wessely \& Welleba (1941) resolved $D L-\alpha, \alpha^{\prime}-$ 
diethyl-4,4'-dihydroxybibenzyl (DL-DEA, 'isohexoestrol'), and found that the dextro-isomer was more potent as an oestrogen in rats than the laevo-isomer and, moreover, that the activity of the racemic mixture was rather less than the calculated value for an equal mixture of the pure D- and L-forms, suggesting some sort of inhibitory interaction.

The general finding in antifertility tests of the type conducted here is that the subcutaneous oestrogenic MED, given daily on Days 1 to 3 or 4 to 6 after mating, approximates to the antifertility MED (Emmens, 1965a). This is true for both steroidal and non-steroidal compounds, with a very few exceptions discussed in previous papers. One was meso-DMA, another is clearly erythro-MEA. The antifertility potency of erythro-MEA is, like that of meso-DMA, so much higher than might be anticipated from its oestrogenic activity that it clearly merits further study, as the most potent antifertility compound not manifestly owing its activity to oestrogenic action. Whether this antifertility activity in the rodent is due to anti-oestrogenic action, which the high potencies of these compounds tend to suggest, remains to be seen.

It is of interest that DL-hexoestrol (DL-DEA) is locally the most potent antioestrogen of the series, but not the most potent antifertility agent. However, it is of greater potency in both regards than is DMs, although of about the same pro-oestrogenic activity.

This series of compounds thus contrasts with the stilbene-4,4'-diols in possessing members with exceptional antifertility potency, which is not seemingly explicable by oestrogenic activity, and also in that the MEAs are anti-oestrogens, while MEs is not (Emmens, Cox \& Martin, 1962).

\section{AGKNOWLEDGMENTS}

This work was supported by grants from the Population Council (U.S.A.) and the Ford Foundation.

\section{REFERENCES}

Emmens, G. W. (1957) Some properties of methylethylstilboestrol. F. Endocr. 16, 148.

EMmens, C. W. (1965a) Oestrogenic, anti-oestrogenic and antifertility activities of various compounds. 7. Reprod. Fert. 9, 277.

Emmens, C. W. (1965b) The oestrogenic and antifertility activities of diethylstilboestrol and dimethylstilboestrol. Acta endocr., Copenh. 49, 83.

Emmens, C. W., Cox, R. I. \& Martin, L. (1959) Oestrogen inhibitors of the stilboestrol series. F. Endocr. $18,372$.

Emmens, C.W., Cox, R.I. \& Martin, L. (1960) Oestrogen inhibition by steroids and other substances. 7. Endocr. 20, 198.

Emmens, C. W., Cox, R. I. \& Marrin, L. (1962) Antioestrogens. Recent Prog. Horm. Res, $18,415$.

Emmens, C. W., Cox, R. I. \& Martin, L. (1964) The oestrogenic and anti-oestrogenic activity of compounds related to diethylstilboestrol. Acta endocr., Copenh. Suppl. 90, 61.

Martin, L., Cox, R. I. \& Emmens, C. W. (1963) Further studies on the effects of oestrogens and antioestrogens on early pregnancy in mice. 7. Reprod. Fert. 5, 239.

Stone, G. M. \& Emmens, C. W. (1964a) The action of oestradiol and dimethyl-stilboestrol on early pregnancy and deciduoma formation in the mouse. F. Endocr. 29, 137.

Stone, G. M. \& Emmens, C. W. (1964b) The effect of oestrogens and anti-oestrogens on deciduoma formation in the rat. 7. Endocr. 29, 147.

Wessely, F., Bauer, A., Chwala, Gh., Plaichinger, I. \& Schonbeck, R. (1948) Uber körperfremde synthetische Ostrogene (3. Mitteilung). Mh. Chem. 79, 596.

Wessely, F. \& Welleba, H. (1941) Uber synthetische Ostrogene, II. Mitteilung: Zur Konfiguration der synthetischen Ostrogene. Chem. Ber. 74, 777. 